\title{
Synthesis and Characterization of Low Loss Dielectric Ceramics Prepared from Composite of Titanate Nanosheets with Barium Ions
}

\author{
Aleksandra Wypych-Puszkarz, ${ }^{1}$ Izabela Bobowska, ${ }^{1}$ \\ Angelika Wrzesinska, ${ }^{1}$ Agnieszka Opasinska, ${ }^{1}$ Waldemar Maniukiewicz, ${ }^{2}$ \\ Piotr Wojciechowski, ${ }^{1}$ and Jacek Ulanski ${ }^{1}$ \\ ${ }^{1}$ Department of Molecular Physics, Faculty of Chemistry, Lodz University of Technology, Żeromskiego 116, 90-924 Lodz, Poland \\ ${ }^{2}$ Institute of General and Ecological Chemistry, Faculty of Chemistry, Lodz University of Technology, \\ Żeromskiego 116, 90-924 Lodz, Poland
}

Correspondence should be addressed to Aleksandra Wypych-Puszkarz; aleksandra.wypych@p.lodz.pl

Received 28 February 2017; Revised 23 April 2017; Accepted 14 May 2017; Published 14 June 2017

Academic Editor: Claude Estournès

Copyright (C) 2017 Aleksandra Wypych-Puszkarz et al. This is an open access article distributed under the Creative Commons Attribution License, which permits unrestricted use, distribution, and reproduction in any medium, provided the original work is properly cited.

\begin{abstract}
We report a strategy for preparing barium titanate precursor, being the composite of titanate nanosheets (TN) with barium ions (Ba$\mathrm{TN}$ ), which subjected to step sintering allows obtaining $\mathrm{TiO}_{2}$ rich barium titanate ceramics of stoichiometry $\mathrm{BaTi}_{4} \mathrm{O}_{9}$ or $\mathrm{Ba}_{2} \mathrm{Ti}_{9} \mathrm{O}_{20}$. These compounds are important in modern electronics due to their required dielectric properties and grains' size that can be preserved in nanometric range. The morphology studies, structural characterization, and dielectric investigations were performed simultaneously in each step of Ba-TN calcinations in order to properly characterize type of obtained ceramic, its grains' morphology, and dielectric properties. The Ba-TN precursor can be sintered at given temperatures, so that its dielectric permittivity can be tuned between 25 and 42 with controlled temperature coefficients that change from negative $32 \mathrm{ppm} /{ }^{\circ} \mathrm{C}$ for Ba-TN sintered at $900^{\circ} \mathrm{C}$ up to positive $37 \mathrm{ppm} /{ }^{\circ} \mathrm{C}$ after calcination at $1300^{\circ} \mathrm{C}$. XRD analysis and Raman investigations performed for the Ba-TN in the temperature range of $900 \div 1250^{\circ} \mathrm{C}$ showed that below $1100^{\circ} \mathrm{C}$ we obtained as a main phase $\mathrm{BaTi}_{4} \mathrm{O}_{9}$, whereas the higher calcinations temperature transformed $\mathrm{Ba}-\mathrm{TN}$ into $\mathrm{Ba}_{2} \mathrm{Ti}_{9} \mathrm{O}_{20}$. Taking into account trend of device miniaturization and nanoscopic size requirements, temperatures of $900^{\circ} \mathrm{C}$ and $1100^{\circ} \mathrm{C}$ seem to be an optimal condition for Ba-TN precursor calcinations that guarantee the satisfactory value of dielectric permittivity $(\varepsilon=26$ and 32) and ceramic grains with a mean size of $\sim 180 \mathrm{~nm}$ and $\sim 550 \mathrm{~nm}$, respectively.
\end{abstract}

\section{Introduction}

Barium titanate ceramic materials have long history in electrotechnical applications. These dielectric oxide ceramics serve as microwave resonators and they are main components of many devices like cellular phones, global positioning system, and environmental monitoring systems on satellites [1]. The main aim of research in this area is to develop new materials or improve properties of already known systems (i.e., reducing dielectric loss and increasing dielectric permittivity). Recent revolutionary changes in wireless communication were achieved by reducing size and cost of components made from improved microwave ceramics. Wide variety of polytitanates has been synthesized and characterized up to now. Among them, particularly a $\mathrm{BaO}-\mathrm{TiO}_{2}$ system with $\mathrm{Ti}$ rich region is interesting because it exhibits eligible electrical properties like good electrical permittivity and low dielectric loss at radio frequencies. $\mathrm{BaTi}_{4} \mathrm{O}_{9}, \mathrm{BaTi}_{5} \mathrm{O}_{11}$, and $\mathrm{Ba}_{2} \mathrm{Ti}_{9} \mathrm{O}_{20}$ are prominent low loss dielectric compounds in this group. $\mathrm{BaTi}_{4} \mathrm{O}_{9}$ as dielectric ceramic was for the first time reported by Masse et al. [2] at early 1970 and had a huge contribution to a breakthrough in dielectric resonators ceramic technology. Conventional method for the preparation of $\mathrm{BaTi}_{4} \mathrm{O}_{9}$ is the solid state ceramic route by ball milling of 
stoichiometric amounts of $\mathrm{BaCO}_{3}$ and $\mathrm{TiO}_{2}$ for about 24 hours $[3,4]$ and sintering at about $1100^{\circ} \mathrm{C}$. It is then again ball milled, pelletized, and sintered at about $1350^{\circ} \mathrm{C}$ to achieve densification of the ceramic body. Wet chemical methods, such as oxalate [5] and citrate route [6] as well as modified Pechini method [7], were also applied for $\mathrm{BaTi}_{4} \mathrm{O}_{9}$ powders preparation. Cernea et al. [5] obtained $\mathrm{BaTi}_{4} \mathrm{O}_{9}$ from oxalates and documented its stable dielectric properties: dielectric permittivity $\varepsilon=38$, quality factor $Q=3800 \div 4000$ at $6 \div 7 \mathrm{GHz}$, and temperature coefficient $\tau_{f}=11 \mathrm{ppm} /{ }^{\circ} \mathrm{C}$. Pure $\mathrm{BaTi}_{4} \mathrm{O}_{9}$ suffers from relatively high values of temperature coefficient, so it is not very suitable as dielectric resonator. Hence the dielectric properties of $\mathrm{BaTi}_{4} \mathrm{O}_{9}$ phase are often modified by using different additives [8]. $\mathrm{BaTi}_{5} \mathrm{O}_{11}$ synthesis was for the first time described by Tillmanns, but it was not pure phase but mixed with rutile [9]. Single-phase $\mathrm{BaTi}_{5} \mathrm{O}_{11}$ was prepared by wet chemical methods like citrate route [10] or sol-gel [11]. This phase is stable under heating up to $1200^{\circ} \mathrm{C}$, then, it decomposes into $\mathrm{TiO}_{2}, \mathrm{Ba}_{2} \mathrm{Ti}_{9} \mathrm{O}_{20}$, and/or $\mathrm{BaTi}_{4} \mathrm{O}_{9}$. $\mathrm{BaTi}_{5} \mathrm{O}_{11}$ phase has higher dielectric constant and quality factor compared to $\mathrm{BaTi}_{4} \mathrm{O}_{9}$; however the values of $\tau_{f}$ are also higher. Fukui et al. prepared $\mathrm{BaTi}_{5} \mathrm{O}_{11}$ by sol-gel method after heating at $1120^{\circ} \mathrm{C}$ for 48 hours. Obtained samples exhibited dielectric permittivity equal to $42, Q \times f>60,000 \mathrm{GHz}$, and $\tau_{f}=39 \mathrm{ppm} /{ }^{\circ} \mathrm{C}[12] . \mathrm{Ba}_{2} \mathrm{Ti}_{9} \mathrm{O}_{20}$ can be conventionally synthesized by mixing $\mathrm{BaCO}_{3}$ and $\mathrm{TiO}_{2}$ in appropriate stoichiometry and calcined at about $1200^{\circ} \mathrm{C}$, again milled, pelletized, and sintered at about $1400^{\circ} \mathrm{C}$ for 3 hours [13]. $\mathrm{Ba}_{2} \mathrm{Ti}_{9} \mathrm{O}_{20}$ obtained by solid state synthesis usually coexists with $\mathrm{BaTi}_{4} \mathrm{O}_{9}$ phase as it is thermodynamically stable in the vicinity of the desired composition. However, pure phase synthesis was achieved by wet chemistry methods. Lu et al. [11] described synthesis based on mixing methanol solution of barium hydroxide with titania sol obtained from hydrolysis of titanium alkoxide. Obtained xerogel was stepwise heated up to $1100^{\circ} \mathrm{C}$ giving $\mathrm{BaTi}_{5} \mathrm{O}_{11}$ phase, while prolonged heating at $1200^{\circ} \mathrm{C}$ gave pure $\mathrm{Ba}_{2} \mathrm{Ti}_{9} \mathrm{O}_{20}$. Fang et al. [14] prepared $\mathrm{Ba}_{2} \mathrm{Ti}_{9} \mathrm{O}_{20}$ in reaction of $\mathrm{BaTi}_{4} \mathrm{O}_{9}$ with $\mathrm{TiO}_{2}$ and sintering at $1390^{\circ} \mathrm{C}$. Obtained sample showed grain size of about 2-3 micrometers and high sintered density of $99 \%$. The dielectric permittivity was equal to 39 , quality factor was $42000 \mathrm{GHz}$, and the temperature coefficient reached $5 \mathrm{ppm} /{ }^{\circ} \mathrm{C} . \mathrm{BaTi}_{4} \mathrm{O}_{9}$ and $\mathrm{Ba}_{2} \mathrm{Ti}_{9} \mathrm{O}_{20}$ have similar values of dielectric permittivity and quality factors. $\mathrm{BaTi}_{4} \mathrm{O}_{9}$ has temperature coefficient close to zero and is always positive, while reported values of $\tau_{f}$ for $\mathrm{Ba}_{2} \mathrm{Ti}_{9} \mathrm{O}_{20}$ are close to zero as well as being negative in some reports [10].

The method of mixing of two low loss ceramic materials with positive and negative temperature coefficient has become well known [15]. This kind of approach is very convenient for preparation of new materials with desired properties by simple selection of proper components. However, very often it is difficult to obtain material with expected intermediate properties because it is impossible to retain individual character of components during sintering process. Thus, development of new precursors of barium titanates and study of their temperature transformation and dielectric properties are still very attractive.
The aim of this work was to develop a method for $\mathrm{TiO}_{2}$ rich barium titanates synthesis by employing titanate nanosheets (TN). They have an orthorhombic layered structure that is composed of corrugated host layers of edgeshared octahedra and interlayer (tetramethyl)ammonium ions $\left(\mathrm{TMA}^{+}\right)$compensating for the negative charge which arises from substitution of lower valence metal ions or vacancies of $\mathrm{Ti}$ [16]. These $\mathrm{TMA}^{+}$ions are exchangeable with a variety of inorganic and organic ions and in this way the TN is an ideal candidate for host-guest chemistry as well as ion exchange [17]. The ion exchangeability also provided the opportunity to prepare precursor of ceramics. For example, potassium hexatitanate $\left(\mathrm{K}_{2} \mathrm{Ti}_{6} \mathrm{O}_{13}\right)$ was prepared by ion exchange, followed by heat treatment at $600^{\circ} \mathrm{C}$ [18]. Taking this into consideration, in this work we applied $\mathrm{TN}$ in ion exchange process to immobilize barium ions from solution. The obtained by this way composite, under a thermal treatment in moderate temperature in air, transformed to $\mathrm{BaTi}_{4} \mathrm{O}_{9}, \mathrm{BaTi}_{5} \mathrm{O}_{11}$, and $\mathrm{Ba}_{2} \mathrm{Ti}_{9} \mathrm{O}_{20}$ phases with desired dielectric properties.

\section{Experimental Section}

All reagents were used as received without further purification.

Synthesis. $250 \mathrm{ml}$ aqueous solution of barium acetate monohydrate $(5.45 \mathrm{~g} ; 20 \mathrm{~mol}$, purchased from Polish Chemical Reagents, POCH, Gliwice, Poland) was mixed with $250 \mathrm{ml}$ aqueous colloidal solution of titanate nanosheets, TN $(2.5 \mathrm{~g} ; R=$ $0,6)$. The details of preparation and characterization of TN have been reported elsewhere [19]. After mixing solutions, ion exchange reaction between (tetramethyl)ammonium ions from $\mathrm{TN}$ and barium cations from barium acetate in aqueous environment led to precipitation of the powder. The mixture was heated for $10 \mathrm{~h}$ at room temperature under stirring and next without stirring for $10 \mathrm{~h}$ at $90^{\circ} \mathrm{C}$. After the reaction, the precipitate was separated by centrifugation, washed with water until $\mathrm{pH} 7$, and dried under vacuum. The total yield of dried organic-inorganic powder was $2.3 \mathrm{~g}$ and it is labeled as $\mathrm{Ba}-\mathrm{TN}$ or precursor of barium titanate. The Ba-TN powder after reaction was subjected to calcination at $500^{\circ} \mathrm{C}$ for 1 hour and pressed to get a pellet under pressure of $436 \mathrm{MPa}$ for $10 \mathrm{~min}$. Based on thermogravimetric measurement (data not shown) temperature of $500^{\circ} \mathrm{C}$ was chosen as an optimal one that allows a decomposition of the organic part of the precursor and the evaporation of volatile products from the sample. The higher temperatures allow for thermal diffusion of the reagents throughout the volume to facilitate the reaction that produces barium titanate ceramic. The pellet was sintered at $900^{\circ} \mathrm{C}$ for 4 hours and then subsequently at $950^{\circ} \mathrm{C}, 1000^{\circ} \mathrm{C}, 1050^{\circ} \mathrm{C}, 1100^{\circ} \mathrm{C}, 1150^{\circ} \mathrm{C}, 1200^{\circ} \mathrm{C}, 1250^{\circ} \mathrm{C}$, and $1300^{\circ} \mathrm{C}$ for $2 \mathrm{~h}$ in each temperature. The time of sintering was chosen according to research of Pfaff who found that at temperature higher than $900^{\circ} \mathrm{C}$ a densification parameter of $\mathrm{BaTi}_{4} \mathrm{O}_{9}$ is constant after two hours of heat treatment [20]. During the applied step sintering procedure the mean particle diameter was investigated and pellets' green density calculated simultaneously with its phase transformation and dielectric properties studies. 


\section{Characterization}

Raman investigations were performed using a Fourier Transform Raman spectrometer (Bruker). All spectra were recorded in the macrochamber light scattering mode; the Raman spectra were obtained at $20^{\circ} \mathrm{C}$ using the $\mathrm{Nd}$ :YAG laser wavelength $\lambda=1064 \mathrm{~nm}$.

Room temperature powder X-ray diffraction patterns were collected using a PANalytical X'Pert Pro MPD diffractometer in the Bragg-Brentano reflection geometry. Copper $\mathrm{CuK}_{\alpha}$ radiation was used from a sealed tube. Data were collected in the $2 \theta$ range $5-90^{\circ}$ with a step of $0.0167^{\circ}$ and an exposure per step of $20 \mathrm{~s}$. The samples were spun during data collection to minimize preferred orientation effects. For phase analysis, the PANalytical High Score Plus software package was used combined with the International Centre for Diffraction Data's (JCPDS) powder diffraction file (PDF-2 ver. 2009) database of standard reference materials.

Particle sizes of Ba-TN obtained in different step of calcination were estimated from SEM images that were collected using a Hitachi S3400N scanning electron microscope with accelerating voltage of $25000 \mathrm{~V}$.

The dielectric properties of synthesized sample were investigated using a Novocontrol GmbH Concept 40 broadband dielectric spectrometer equipped with Quatro Cryosystem in the frequency range of $10^{-1} \div 10^{6} \mathrm{~Hz}$ and in the temperature range of $-140^{\circ} \mathrm{C} \div 200^{\circ} \mathrm{C}$ (in steps of $10^{\circ} \mathrm{C}$ ). The obtained complex dielectric function $\left(\varepsilon^{*}\right)$ was measured by

$$
\varepsilon^{*}=\varepsilon^{\prime}-i \varepsilon^{\prime \prime},
$$

where $\varepsilon^{\prime}$ and $\varepsilon^{\prime \prime}$ are the real and imaginary parts, respectively.

Before electric measurement each pellet was additionally dried at $90^{\circ} \mathrm{C}$ under reduced pressure in order to exclude the influence of the humidity. To provide good contact between the sample and external electrodes during electrical investigations, $150 \mathrm{~nm}$ thick gold electrodes were deposited on both sites of the pellet. The densities of the samples sintered at different temperatures were evaluated based on the external dimensions and mass of the pellets. The relative density of pellets was estimated through comparison with theoretical crystallographic density of the major crystallographic phase defined from Raman and XRD investigations.

\section{Results and Discussion}

Raman spectra of the samples before and after the ion exchange are shown in Figure 1. For TN in Figure 1(a), the spectrum is essentially the same as the data reported for titanate nanosheets intercalated by $\mathrm{TMA}^{+}$ions [21]. According to the literature $[21,22]$ Raman bands observed at $275 \mathrm{~cm}^{-1}, 384 \mathrm{~cm}^{-1}, 448 \mathrm{~cm}^{-1}, 662 \mathrm{~cm}^{-1}, 883 \mathrm{~cm}^{-1}$, and $899 \mathrm{~cm}^{-1}$ can be attributed to the Ti-O lattice vibrations in the $\mathrm{TiO}_{6}$ octahedral host layers and the strong peaks at $756 \mathrm{~cm}^{-1}$ and $954 \mathrm{~cm}^{-1}$ were related to (tetramethyl)ammonium ions $\left(\mathrm{TMA}^{+}\right)$. These two peaks just disappear after the exchange reaction-replacement (Figure 1(b)) of $\mathrm{TMA}^{+}$ions in $\mathrm{TN}$ by barium ions. The Raman vibration assigned to Ti-O still exists which is a convenient proof that $2 \mathrm{D}$ structure of $\mathrm{TN}$

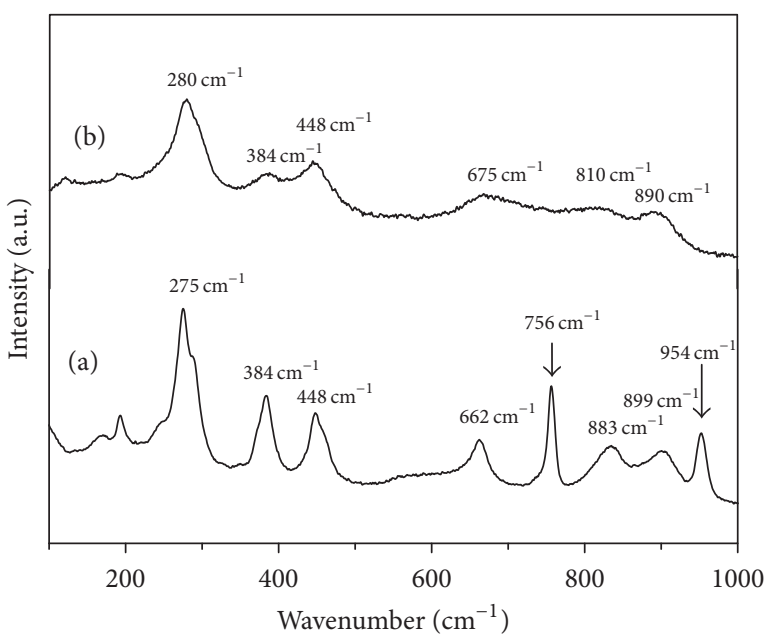

FIGURE 1: Raman spectra of dried (a) titanate nanosheets, TN, and (b) precipitate $\mathrm{Ba}-\mathrm{TN}$.

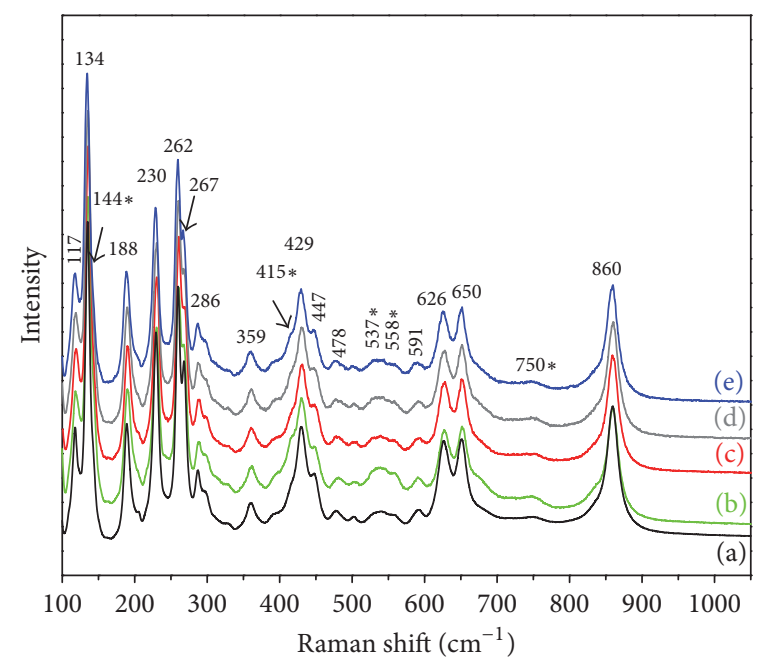

FIgURE 2: Raman spectra collected at room temperature for Ba-TN after sintering at (a) $900^{\circ} \mathrm{C}$, (b) $950^{\circ} \mathrm{C}$, (c) $1000^{\circ} \mathrm{C}$, (d) $1050^{\circ} \mathrm{C}$, and (e) $1100^{\circ} \mathrm{C}$. Raman bands characteristic for $\mathrm{BaTi}_{5} \mathrm{O}_{11}$ are labeled by stars.

was preserved. However, peaks at $600-1000 \mathrm{~cm}^{-1}$ spectral region shift to lower frequencies which could be affected by a presence of $\mathrm{Ba}^{2+}$ ions in the interlayer of TN [23]. Obtained powder of Ba-TN could be considered as a precursor of $\mathrm{BaTi}_{4} \mathrm{O}_{9}$ since, after the thermal treatment at $900^{\circ} \mathrm{C}$ for $4 \mathrm{~h}$, it gave the characteristic Raman spectrum for this compound (Figure 2(a)). One can observe bands located at $117 \mathrm{~cm}^{-1}$, $134 \mathrm{~cm}^{-1}, 188 \mathrm{~cm}^{-1}, 230 \mathrm{~cm}^{-1}, 262 \mathrm{~cm}^{-1}, 267 \mathrm{~cm}^{-1}, 286 \mathrm{~cm}^{-1}$, $359 \mathrm{~cm}^{-1}, 429 \mathrm{~cm}^{-1}, 447 \mathrm{~cm}^{-1}, 478 \mathrm{~cm}^{-1}, 591 \mathrm{~cm}^{-1}, 626 \mathrm{~cm}^{-1}$, $650 \mathrm{~cm}^{-1}$, and $860 \mathrm{~cm}^{-1}$ that are characteristic for $\mathrm{BaTi}_{4} \mathrm{O}_{9}$ [24] according to work of Rössel et al. Further sintering at temperature range between $950^{\circ} \mathrm{C}$ and $1100^{\circ} \mathrm{C}$, during $2 \mathrm{~h}$ at each temperature, gave the Raman spectra of the same intensity and identical Raman bands as observed for Ba-TN sintered at $900^{\circ} \mathrm{C}$ (see Figure $2(\mathrm{~b}-\mathrm{e})$ ). These results allow for conclusion that there was not any phase transformation 


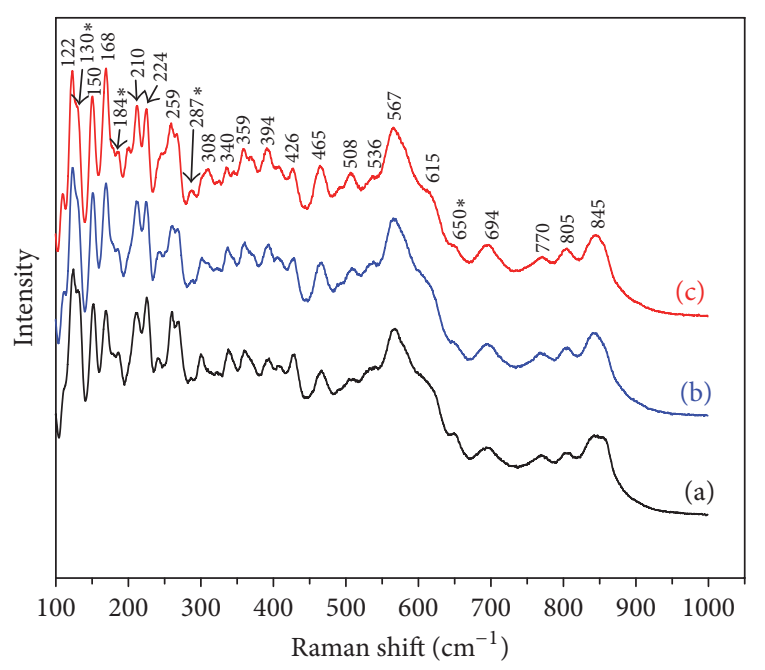

FIGURE 3: Raman spectra collected at room temperature for Ba-TN after sintering at (a) $1150^{\circ} \mathrm{C}$, (b) $1200^{\circ} \mathrm{C}$, and (c) $1250^{\circ} \mathrm{C}$. Raman bands assigned to $\mathrm{BaTi}_{4} \mathrm{O}_{9}$ are marked by stars.

during the applied thermal treatment in the temperature range between $900^{\circ} \mathrm{C}$ and $1100^{\circ} \mathrm{C}$. Moreover sharpness of Raman peaks denotes well crystallized structure that was independently revealed by X-ray diffraction studies. Detailed analysis of the recorded Raman spectra allowed observing bands of lower intensity which are located at $144 \mathrm{~cm}^{-1}$, $415 \mathrm{~cm}^{-1}, 537 \mathrm{~cm}^{-1}, 558 \mathrm{~cm}^{-1}$, and $750 \mathrm{~cm}^{-1}$. They are marked by stars (in Figure 2) and their occurrence indicates the presence of barium titanate of stoichiometry $\mathrm{BaTi}_{5} \mathrm{O}_{11}$.

Figure 3 shows Raman spectra for $\mathrm{Ba}-\mathrm{TN}$ precursor sintered for $2 \mathrm{~h}$ at (a) $1150^{\circ} \mathrm{C}$, (b) $1200^{\circ} \mathrm{C}$, and (c) $1250^{\circ} \mathrm{C}$, on which one can observe a significant change of the spectra as compared to Raman spectrum of precursor sintered up to $1100^{\circ} \mathrm{C}$. In Figure $3(\mathrm{a}-\mathrm{c})$ there are Raman bands characteristic for $\mathrm{BaTi}_{4} \mathrm{O}_{9}$ phase that almost totally disappeared with exception of the bands located at $130 \mathrm{~cm}^{-1}, 184 \mathrm{~cm}^{-1}, 287 \mathrm{~cm}^{-1}$, and $650 \mathrm{~cm}^{-1}$. For the precursor sintered at the temperatures of $1150^{\circ} \mathrm{C}$ and higher, there are detected Raman bands located at $122 \mathrm{~cm}^{-1}, 150 \mathrm{~cm}^{-1}, 168 \mathrm{~cm}^{-1}, 210 \mathrm{~cm}^{-1}, 224 \mathrm{~cm}^{-1}$, $259 \mathrm{~cm}^{-1}, 308 \mathrm{~cm}^{-1}, 340 \mathrm{~cm}^{-1}, 359 \mathrm{~cm}^{-1}, 394 \mathrm{~cm}^{-1}, 426 \mathrm{~cm}^{-1}$, $465 \mathrm{~cm}^{-1}, 508 \mathrm{~cm}^{-1}, 536 \mathrm{~cm}^{-1}, 567 \mathrm{~cm}^{-1}, 615 \mathrm{~cm}^{-1}, 694 \mathrm{~cm}^{-1}$, $770 \mathrm{~cm}^{-1}, 805 \mathrm{~cm}^{-1}$, and $845 \mathrm{~cm}^{-1}$ that can be assigned to barium titanate of stoichiometry $\mathrm{Ba}_{2} \mathrm{Ti}_{9} \mathrm{O}_{20}$. Raman spectra shown in Figure $3(\mathrm{a}-\mathrm{c})$ have a very good agreement with work of Javadpour and Eror [25], who detected by Raman spectroscopy $\mathrm{Ba}_{2} \mathrm{Ti}_{9} \mathrm{O}_{20}$ phase after long treatment at $1200^{\circ} \mathrm{C}$, as well as with work of Xu et al. [26].

The XRD diffraction patterns of the Ba-TN samples after sintering at $900^{\circ} \mathrm{C}-1250^{\circ} \mathrm{C}$ are shown in Figure 4. The $\mathrm{XRD}$ analysis revealed that below $1100^{\circ} \mathrm{C}$ we observed as a main phase orthorhombic $\mathrm{BaTi}_{4} \mathrm{O}_{9}$ (JCPDS number 340070) and the presence of $\mathrm{BaTi}_{5} \mathrm{O}_{11}$ (JCPDS number 350805) as secondary phase. The increase of the calcination temperature above $1100^{\circ} \mathrm{C}$ caused the phase transition and crystallization of $\mathrm{Ba}_{2} \mathrm{Ti}_{9} \mathrm{O}_{20}$ (JCPDS number 40-0405), but the peaks attributed to $\mathrm{BaTi}_{4} \mathrm{O}_{9}$ were still visible. These results
TABLE 1: Phase composition [\% w/w] of Ba-TN sintered at different temperatures estimated from XRD patterns.

\begin{tabular}{lccccc}
\hline Phase & $900^{\circ} \mathrm{C}$ & $1100^{\circ} \mathrm{C}$ & $\begin{array}{c}\text { Temp. } \\
1150^{\circ} \mathrm{C}\end{array}$ & $1200^{\circ} \mathrm{C}$ & $1250^{\circ} \mathrm{C}$ \\
\hline $\mathrm{BaTi}_{4} \mathrm{O}_{9}$ & 66 & 42 & 8 & 6 & 6 \\
$\mathrm{BaTi}_{5} \mathrm{O}_{11}$ & 34 & 45 & - & - & - \\
$\mathrm{Ba}_{2} \mathrm{Ti}_{9} \mathrm{O}_{20}$ & - & 13 & 92 & 94 & 94 \\
\hline
\end{tabular}

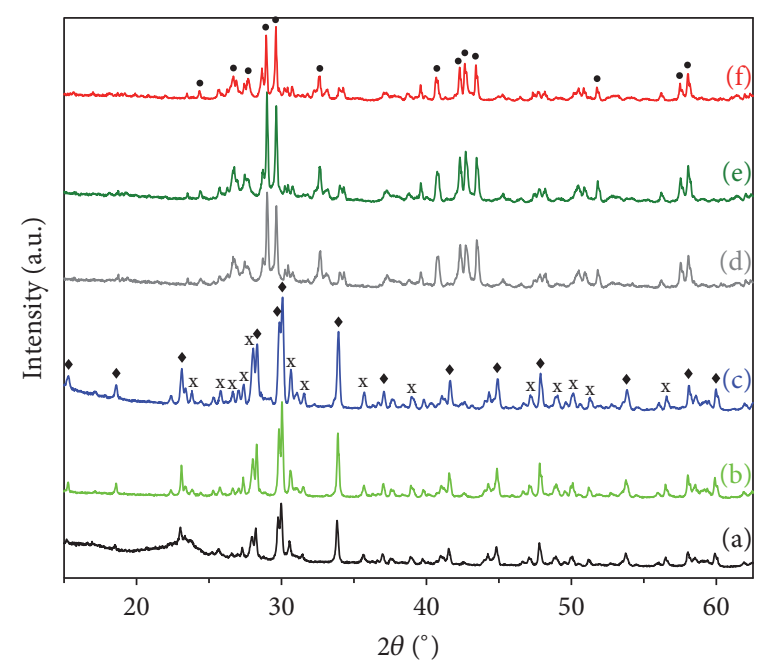

FIGURE 4: XRD patterns of Ba-TN after sintering at (a) $900^{\circ} \mathrm{C}$, (b) $950^{\circ} \mathrm{C}$, (c) $1100^{\circ} \mathrm{C}$, (d) $1150^{\circ} \mathrm{C}$, (e) $1200^{\circ} \mathrm{C}$, and (f) $1250^{\circ} \mathrm{C}\left(\diamond: \mathrm{BaTi}_{4} \mathrm{O}_{9}\right.$; $\mathrm{x}: \mathrm{BaTi}_{5} \mathrm{O}_{11} ; \mathrm{Ba}_{2} \mathrm{Ti}_{9} \mathrm{O}_{20}$ ).

are in good agreement with Raman spectra, where phase transformation of $\mathrm{BaTi}_{4} \mathrm{O}_{9}$ into $\mathrm{Ba}_{2} \mathrm{Ti}_{9} \mathrm{O}_{20}$ was also observed for $\mathrm{Ba}-\mathrm{TN}$ sintered at temperature higher than $1100^{\circ} \mathrm{C}$. The quantitative phases composition of the studied samples was estimated on the basis of XRD spectra using the reference intensity ratio (RIR) method [27] and the obtained data are gathered in Table 1. The RIR method involves comparing the intensity of one or more peaks of a phase with the intensity of a peak of a standard (usually the corundum 113 reflection) in a 50:50 mixture by weight. For the processing of diffraction data the PANalytical High Score Plus software package was used.

It was found that in the effect of sintering at $900^{\circ} \mathrm{C}$ the $\mathrm{BaTi}_{4} \mathrm{O}_{9}$ phase constituted $66 \% \mathrm{w} / \mathrm{w}$ and $\mathrm{BaTi}_{5} \mathrm{O}_{11} 34 \% \mathrm{w} / \mathrm{w}$ of the sample. An increase of the temperature to $1100^{\circ} \mathrm{C}$ induced certain changes in phase composition. A proportion of $\mathrm{BaTi}_{4} \mathrm{O}_{9}$ to $\mathrm{BaTi}_{5} \mathrm{O}_{11}$ phases slightly changed into ratio $42 / 45 \% \mathrm{w} / \mathrm{w}$ and a new phase showed up $-\mathrm{Ba}_{2} \mathrm{Ti}_{9} \mathrm{O}_{20}$ with the content of $11 \% \mathrm{w} / \mathrm{w}$. The rise of the temperature of only $50^{\circ} \mathrm{C}$ resulted in very significant changes in phase composition. $\mathrm{BaTi}_{5} \mathrm{O}_{11}$ phase disappeared completely and new phase, that is, $\mathrm{Ba}_{2} \mathrm{Ti}_{9} \mathrm{O}_{20}$ with a content of $92 \% \mathrm{w} / \mathrm{w}$ and $\mathrm{BaTi}_{4} \mathrm{O}_{9}$ with a content of $8 \% \mathrm{w} / \mathrm{w}$, was observed. Further increase of sintering temperature up to $1200^{\circ} \mathrm{C}$ and $1250^{\circ} \mathrm{C}$ did not influence significantly the phase composition. The $\mathrm{Ba}_{2} \mathrm{Ti}_{9} \mathrm{O}_{20} / \mathrm{BaTi}_{4} \mathrm{O}_{9}$ weight ratio was estimated at $94 / 6 \% \mathrm{w} / \mathrm{w}$ for higher sintering temperatures. The observed changes 


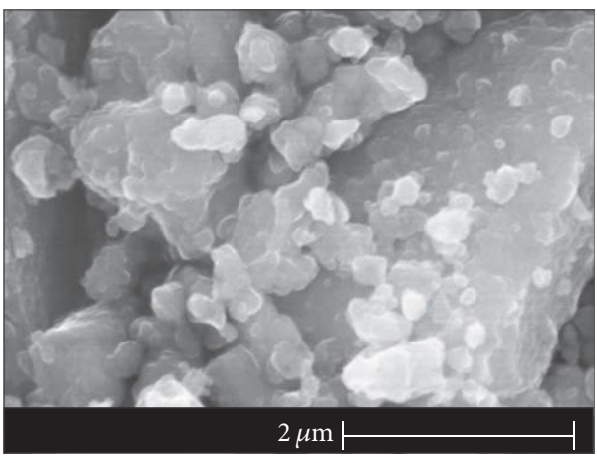

(a)

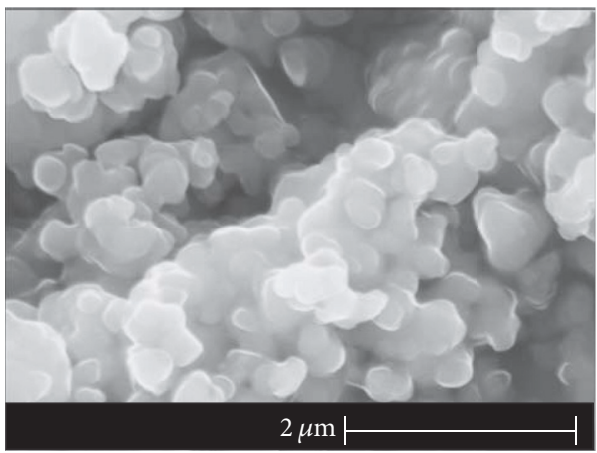

(c)

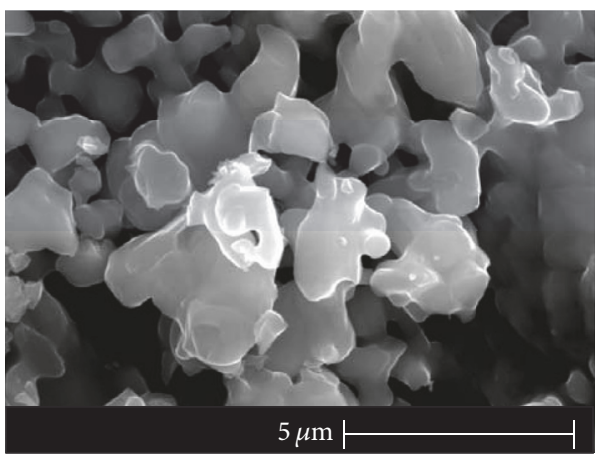

(e)

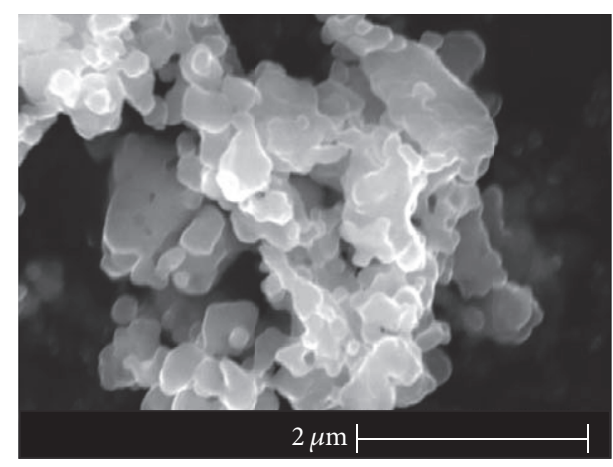

(b)

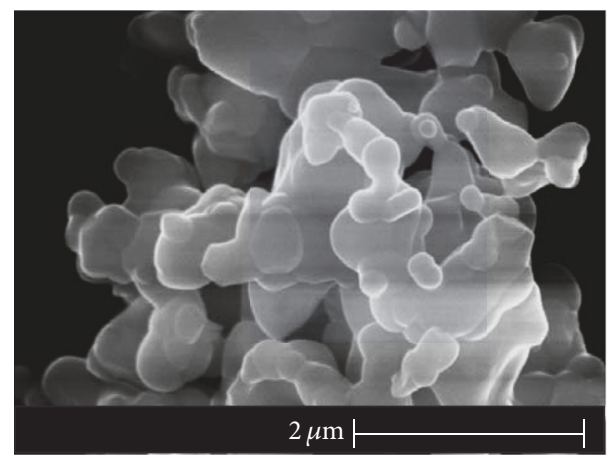

(d)

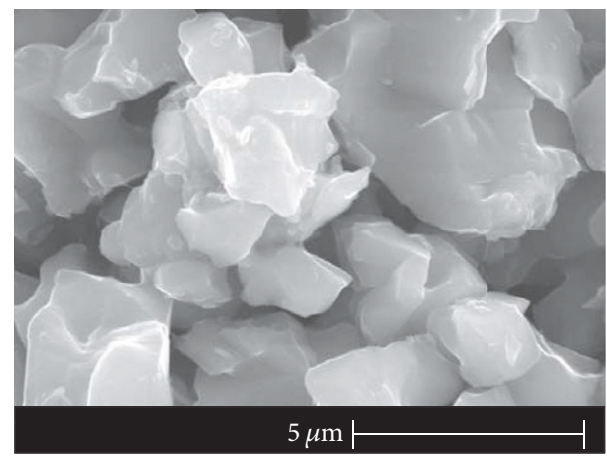

(f)

Figure 5: SEM images of Ba-TN subjected to step sintering at (a) $500^{\circ} \mathrm{C}$, (b) $950^{\circ} \mathrm{C}$, (c) $1050^{\circ} \mathrm{C}$, (d) $1100^{\circ} \mathrm{C}$ (magnification $10 \mathrm{k}$ ), (e) $1150^{\circ} \mathrm{C}$, and (f) $1200^{\circ} \mathrm{C}$ (magnification $25 \mathrm{k}$ ), collected with accelerating voltage $25 \mathrm{kV}$.

are in good agreement with observation made by Raman spectroscopy. However, the scattering intensities of $\mathrm{BaTi}_{5} \mathrm{O}_{11}$ and $\mathrm{Ba}_{2} \mathrm{Ti}_{9} \mathrm{O}_{20}$ phases are markedly lower than $\mathrm{BaTi}_{4} \mathrm{O}_{9}$. Thus $\mathrm{Ba}_{2} \mathrm{Ti}_{9} \mathrm{O}_{20}$ phase was not observed by Raman spectroscopy after the sample sintering at the temperature of $1100^{\circ} \mathrm{C}$, but only after treatment at the temperature of $1150^{\circ} \mathrm{C}$ where the domination of this phase was reached.

Figure 5 illustrates SEM images of Ba-TN powder subjected to calcination at $500^{\circ} \mathrm{C}$ for 1 hour and sintering for $2 \mathrm{~h}$ at the temperature range from $950^{\circ} \mathrm{C}$ to $1200^{\circ} \mathrm{C}$. Mean size of grains and standard deviation, evaluated on the basis of SEM images analysis, are presented in Figure 6, in relation to sintering temperature. The grain size of $\mathrm{Ba}-\mathrm{TN}$ precursor annealed at $500^{\circ} \mathrm{C}$ and $950^{\circ} \mathrm{C}$ kept constant value below $200 \mathrm{~nm}$.
After the sintering at the temperature of $1050^{\circ} \mathrm{C}$ the particles were still characterized by narrow size distribution and sphere-like grains morphology; however mean size increased to c.a. $400 \mathrm{~nm}$ and size distribution significantly widened. A shift of sintering temperature to $1100^{\circ} \mathrm{C}$ induced evident changes in morphology; partial coarsening of grains occurred. At the temperature of $1150^{\circ} \mathrm{C}$ and higher, the sphere-like morphology of grains disappeared and irregular agglomerates and large grains were mainly observed. The mean size of grains increases up to about $1.0 \mu \mathrm{m}$ and $1.6 \mu \mathrm{m}$ for the temperatures $1150^{\circ} \mathrm{C}$ and $1200^{\circ} \mathrm{C}$, respectively. In the case of $\mathrm{Ba}-\mathrm{TN}$ sintered at $1200^{\circ} \mathrm{C}$ irregular agglomerates of rounded shape transformed into sharp angular grains. A marked change in grains' size and morphology observed at the temperature above $1100^{\circ} \mathrm{C}$ coincides with the structural 
TABLE 2: Pellets filling percentage and dielectric properties of the Ba-TN precursor sintered at different temperatures.

\begin{tabular}{lccccc}
\hline $\begin{array}{l}\text { Sintering temperature } \\
\text { of Ba-TN precursor }\left[{ }^{\circ} \mathrm{C}\right]\end{array}$ & $\begin{array}{c}\text { Relative } \\
\text { density [\%] }\end{array}$ & $\begin{array}{c}\text { Dielectric constant }(\varepsilon) \\
\text { (at 1 MHz) }\end{array}$ & $\begin{array}{c}\tan (\delta) \\
(\text { at 1 MHz) }\end{array}$ & $\begin{array}{c}\text { Quality factor } \\
(Q) \text { at 1 MHz }\end{array}$ & $\begin{array}{c}\text { Temperature coefficient } \\
\left({ }^{\mathrm{c}}\right) \mathrm{ppm} /{ }^{\circ} \mathrm{C}\end{array}$ \\
\hline 900 & $64^{\mathrm{a}}$ & 25,7 & $4,2 * 10^{-4}$ & 2300 & -32 \\
1100 & $78^{\mathrm{a}}$ & 32,4 & $8,7 * 10^{-5}$ & 11500 & -18 \\
1200 & $85^{\mathrm{b}}$ & 35,1 & $7,7 * 10^{-5}$ & 13000 & 7 \\
1250 & $88^{\mathrm{b}}$ & 37,6 & $7,5 * 10^{-5}$ & 13300 & 33 \\
1300 & $98^{\mathrm{b}}$ & 42,0 & $1,5 * 10^{-5}$ & 66600 & 37 \\
\hline
\end{tabular}

${ }^{\mathrm{a}}$ Value calculated in regard to theoretical density of $\mathrm{BaTi}_{4} \mathrm{O}_{9} ;{ }^{\mathrm{b}}$ value calculated in regard to theoretical density of $\mathrm{Ba}_{2} \mathrm{Ti}_{9} \mathrm{O}_{20} ;{ }^{\mathrm{c}}$ value calculated in a temperature range from $-130^{\circ} \mathrm{C}$ to $100^{\circ} \mathrm{C}$.

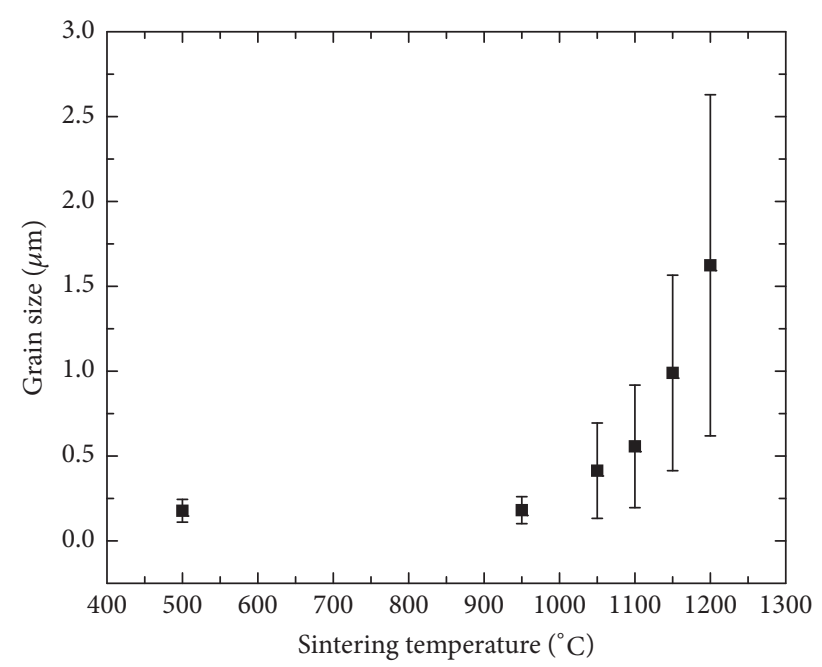

Figure 6: Grain size dependence as a function of calcination temperature.

transformation observed by Raman spectroscopy and XRD analysis.

The dielectric parameters of the sintered precursor are strictly dependent on densification behavior, that is, shrinkage of formed discs upon heating. From this reason the relative density and percentage of pellets' filling were investigated as a function of applied step sintering. It is well known that higher temperature of sintering rises these parameters; however in Figures 7(a) and 7(b) one can find some regimes that are distinguished by different behavior below and above temperature of $1050^{\circ} \mathrm{C}$. Below this temperature the increase of relative density and percentage of pellets' filling is slow, whereas above $1050^{\circ} \mathrm{C}$ these parameters rise substantially. This caused a rapid pellet's contraction that can be connected with an acceleration of diffusion in solid state and initiation of neck formation between crystallites above this temperature, that is, in agreement with grains' morphology changes at $1100^{\circ} \mathrm{C}$ revealed by SEM investigations. Above this temperature there is a phase transformation of main $\left(\mathrm{BaTi}_{4} \mathrm{O}_{9}\right)$ and secondary $\left(\mathrm{BaTi}_{5} \mathrm{O}_{11}\right)$ phases into $\mathrm{Ba}_{2} \mathrm{Ti}_{9} \mathrm{O}_{20}$ and concomitant further increase of pellets' relative density. The percentage of pellets' filling was calculated taking into account the theoretic density values of $\mathrm{BaTi}_{4} \mathrm{O}_{9}$ and $\mathrm{Ba}_{2} \mathrm{Ti}_{9} \mathrm{O}_{20}$ that are equal $4,52 \mathrm{~g} / \mathrm{cm}^{3}$ (Pearson's Crystal Data, ICDD 04-007-2688) and $4,58 \mathrm{~g} / \mathrm{cm}^{3}$ (crystallographic data, reference code 00-0350051), respectively. Finally after sintering at $1250^{\circ} \mathrm{C}$ calculated relative pellet's density was $4,01 \mathrm{~g} / \mathrm{cm}^{3}$ that corresponds to more than $85 \%$ of $\mathrm{Ba}_{2} \mathrm{Ti}_{9} \mathrm{O}_{20}$ crystallographic density.

To characterize the dielectric properties of sintered at different temperatures $\mathrm{Ba}-\mathrm{TN}$ pellets we applied broadband dielectric spectroscopy which allowed us to determine the following physical properties that are important for ceramic applications: dielectric permittivity $(\varepsilon)$, quality factor $(Q)$ defined as $1 / \tan (\delta)$, and temperature coefficient of resonant frequency $\left(\tau_{\varepsilon}\right)$. Figure 8 shows three-dimensional graphs comprising the temperature-frequency representations of dielectric permittivity for Ba-TN sintered at $900^{\circ} \mathrm{C}$ (Figure $8(\mathrm{a})$ ) and $1200^{\circ} \mathrm{C}$ (Figure $8(\mathrm{~b})$ ), respectively. The graphs clearly show that in very broad temperature and frequency ranges there is a lack of any relaxation process in the material. The increase in these variables at low frequencies and at high temperatures is connected with interfacial polarization or electrode polarization contribution that might be present under these conditions. These graphs are exemplary also for $\mathrm{Ba}-\mathrm{TN}$ precursor sintered in other temperatures.

In Figure 9 the temperature dependence of dielectric permittivity of Ba-TN subjected to sintering at different temperatures is shown. All samples, in $\mathrm{MHz}$ frequencies, are characterized by very stable, flat response over broad range of temperatures (more than $230^{\circ} \mathrm{C}$ ). One can observe an increase of $\varepsilon$ with sintering temperature that is connected to well known relationship between density of the sample and its dielectric properties, according to which higher density results in a higher dielectric permittivity and lower porosity, which improves also quality factor value $Q$. The relative density of ceramic pellets studied by us was varying from 64 to $96 \%$ (Table 2). It means that measured ceramics were partially porous and can be considered as capacitor composed of ceramic and air. Phase composition of measured sample (calculated from XRD, data gathered in Table 1) is another factor influencing dielectric permittivity. In the case of $\mathrm{BaTi}_{4} \mathrm{O}_{9}$ and $\mathrm{Ba}_{2} \mathrm{Ti}_{9} \mathrm{O}_{20}$, the maximum literature values of $\varepsilon$ were equal to 39 [5] and 52 [28], respectively. The BaTN subjected to step sintering in a range of temperatures from $900^{\circ} \mathrm{C}$ to $1300^{\circ} \mathrm{C}$ can be considered as a mixture of tetra- and nonatitanates; thus they are expected to possess intermediate dielectric properties. It can be concluded that $\mathrm{Ba}-\mathrm{TN}$ precursor can be sintered at given temperatures, so that its dielectric permittivity can be tuned between 25 and 


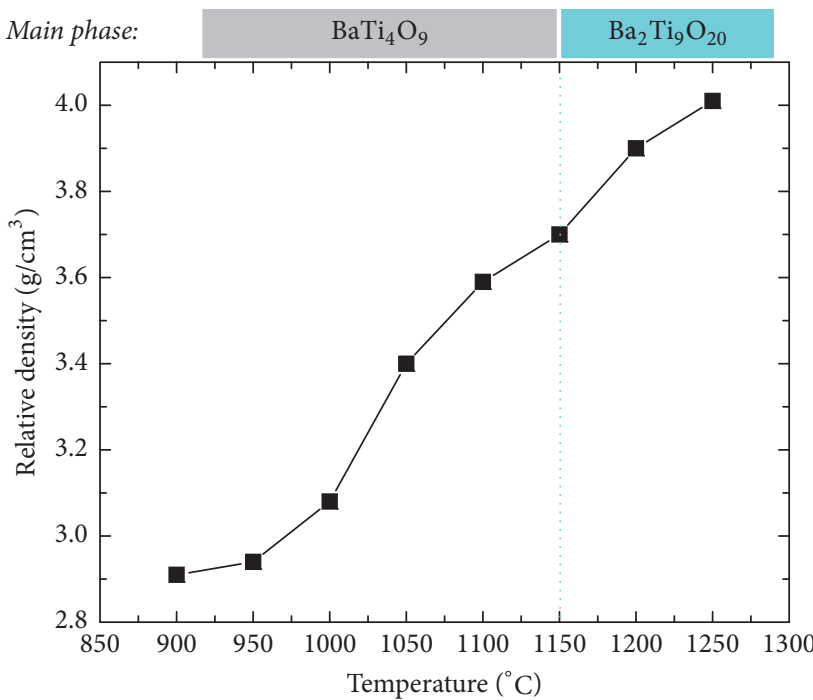

(a)

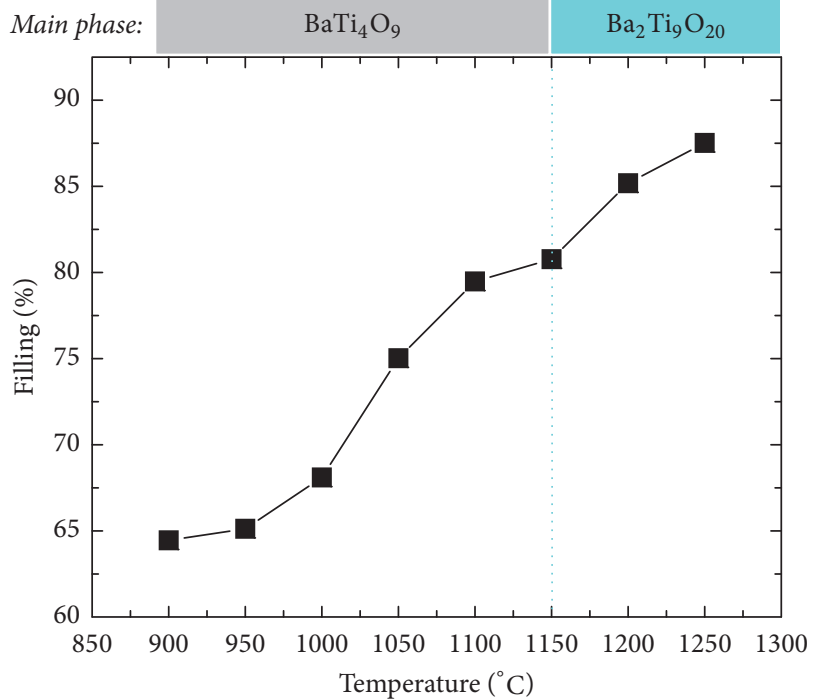

(b)

FiguRE 7: Dependence of pellet's relative density (a) and percentage of pellet's filling (b) on the Ba-TN sintering temperature.

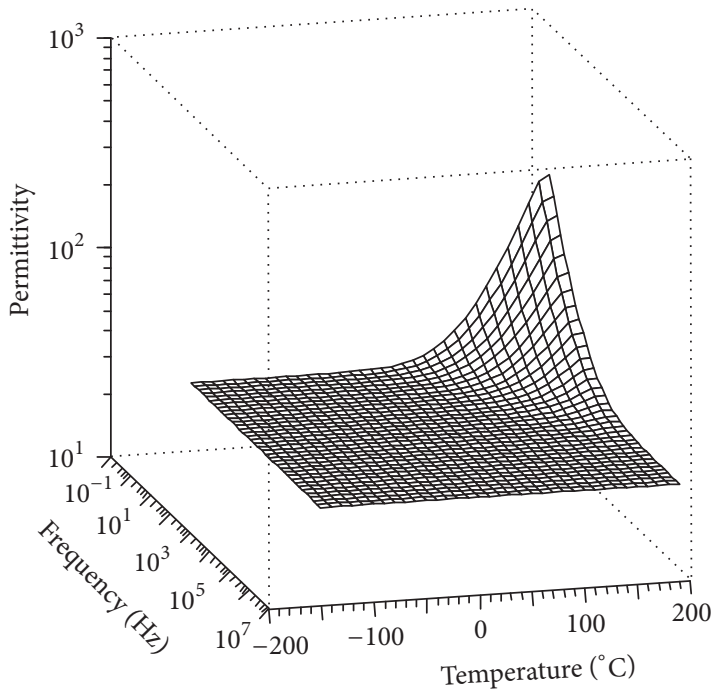

(a)

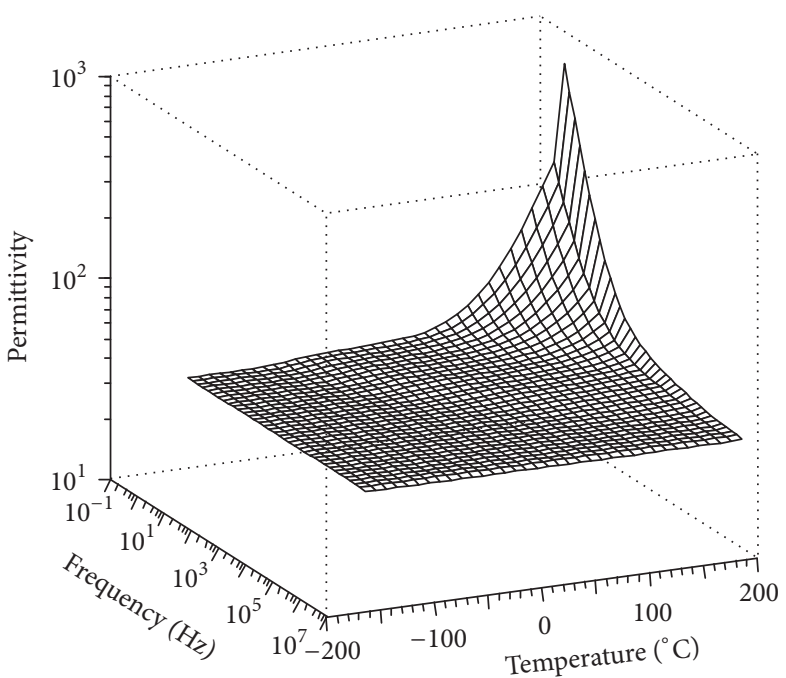

(b)

Figure 8: Temperature-frequency representation of dielectric permittivity Ba-TN sintered at (a) $900^{\circ} \mathrm{C}$ and (b) $1200^{\circ} \mathrm{C}$.

42. Detected values of $\tan (\delta)$, measured at $20^{\circ} \mathrm{C}$ for frequency $1 \mathrm{MHz}$, were also very interesting and vary from $4,2 * 10^{-4}$ (for Ba-TN sintered at $900^{\circ} \mathrm{C}$ ) to $1,5 * 10^{-5}$ (for Ba-TN sintered at $1300^{\circ} \mathrm{C}$ ). The lower value of loss tangent detected for samples sintered at higher temperatures can be connected to higher density of measured pellets. It can be noticed that $Q$ values arise with higher sintering temperature reaching a maximum value of 66,600 for sample sintered at $1300^{\circ} \mathrm{C}$ which exhibits the highest density equal to $4,42 \mathrm{~g} / \mathrm{cm}^{3}$, that is, $98 \%$ of $\mathrm{Ba}_{2} \mathrm{Ti}_{9} \mathrm{O}_{20}$ theoretical density. This can be associated with a change of porosity, that is, higher density of pellets after treatment at higher temperature and it is in agreement with a statement according to which the porosity decreases the quality factor due to the presence of moisture in the pores.

From the representations given in Figure 5, the temperature coefficient $\left(\tau_{\varepsilon}\right)$ was calculated as a function of temperature from $-130^{\circ} \mathrm{C}$ to $100^{\circ} \mathrm{C}$ according to (2)

$$
\left.\tau_{\varepsilon}\right|_{-130^{\circ} \mathrm{C}} ^{100^{\circ} \mathrm{C}}=\frac{1}{\varepsilon_{\left(-130^{\circ} \mathrm{C}\right)}}\left(\frac{\Delta \varepsilon}{\Delta T}\right) \mathrm{ppm} /{ }^{\circ} \mathrm{C} \text {. }
$$

It was observed that temperature coefficients changed from negative, for $\mathrm{Ba}-\mathrm{TN}$ sintered up to $1100^{\circ} \mathrm{C}$ with $\mathrm{BaTi}_{4} \mathrm{O}_{9}$ as a main phase, to positive for $\mathrm{Ba}-\mathrm{TN}$ sintered in a range of 


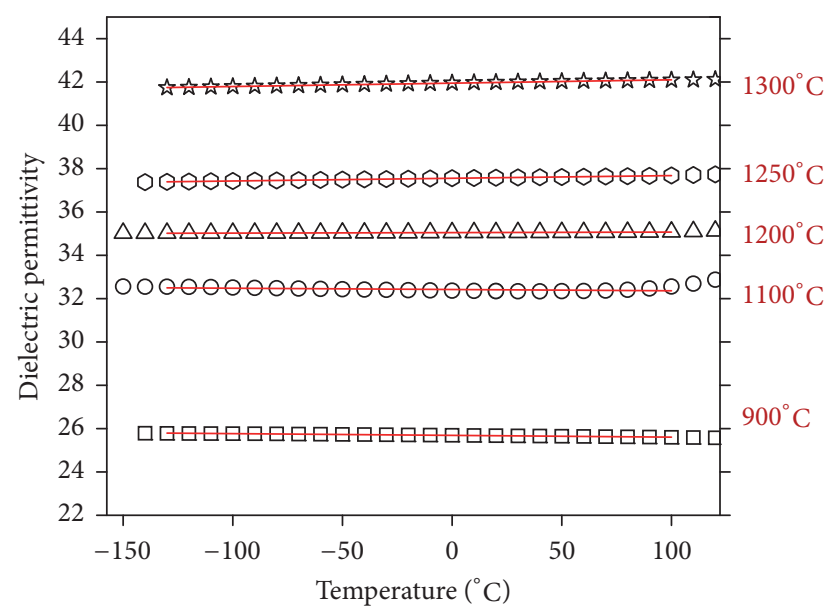

Figure 9: The temperature dependence of dielectric permittivity measured at $1.15 \mathrm{MHz}$ of $\mathrm{Ba}-\mathrm{TN}$ sintered at different temperatures. Red lines correspond to linear fits for calculation of temperature coefficients.

temperatures $1150 \div 1300^{\circ} \mathrm{C}$ with a main phase of $\mathrm{Ba}_{2} \mathrm{Ti}_{9} \mathrm{O}_{20}$. This can be connected with phase transformation of $\mathrm{BaTi}_{4} \mathrm{O}_{9}$ into $\mathrm{Ba}_{2} \mathrm{Ti}_{9} \mathrm{O}_{20}$ and low value of temperature coefficient for barium nonatitanate that was found equal to about $6 \mathrm{ppm} /{ }^{\circ} \mathrm{C}$ [28]. It should be emphasized that the dielectric properties of the investigated ceramics depend considerably on sintering temperature and their microstructures. According to this the temperature coefficient for $\mathrm{Ba}_{2} \mathrm{Ti}_{9} \mathrm{O}_{20}$ may vary between -6 and $38 \mathrm{ppm} /{ }^{\circ} \mathrm{C}[10,29]$. Presented herein are dielectric results which are in agreement with results of Kumar et al. who obtained $\mathrm{BaTi}_{4} \mathrm{O}_{9}$ and $\mathrm{Ba}_{2} \mathrm{Ti}_{9} \mathrm{O}_{20}$ ceramics by the wet chemical gel-carbonate method and found comparable dielectric permittivity, but there was no exact data concerning temperature coefficient values [28].

Obtained within this work are materials which are regarded as three important low loss dielectric ceramics. $\mathrm{BaTi}_{4} \mathrm{O}_{9}$ and $\mathrm{Ba}_{2} \mathrm{Ti}_{9} \mathrm{O}_{20}$ are regarded as stable forms, whereas $\mathrm{BaTi}_{5} \mathrm{O}_{11}$ is a metastable one. The observed by us transformation is in agreement with phase diagram of $\mathrm{BaTiO}_{3}$ $\mathrm{TiO}_{2}$ system [30], where $\mathrm{BaTi}_{4} \mathrm{O}_{9}$ is located in the immediate vicinity of $\mathrm{Ba}_{2} \mathrm{Ti}_{9} \mathrm{O}_{20}$ and both phases appear to be in equilibrium below $1420^{\circ} \mathrm{C}$ for compositions between 80 and $81,8 \mathrm{~mol} \% \mathrm{TiO}_{2}$ in $\mathrm{BaTiO}_{3}-\mathrm{TiO}_{2}$.

\section{Conclusion}

$\mathrm{Ba}-\mathrm{TN}$ precursor obtained from reaction of titanate nanosheets with barium ions was found as an interesting method to obtain barium titanates that exhibit elevated values of dielectric permittivity and low loss tangent in $\mathrm{MHz}$ frequencies. The dielectric properties of this composite can be tailored by suitably adjusting the sintering temperatures. According to this barium titanates of stoichiometry, $\mathrm{BaTi}_{4} \mathrm{O}_{9}$ being the predominant phase and $\mathrm{BaTi}_{5} \mathrm{O}_{11}$ as minor phase below $1150^{\circ} \mathrm{C}$ are present, whereas $\mathrm{Ba}_{2} \mathrm{Ti}_{9} \mathrm{O}_{20}$ is formed at higher temperatures of sintering. The dielectric properties of these ceramics depend considerably on sintering temperature and their microstructures. From this reason structural studies as well as grain morphology and dielectric investigations were carried out simultaneously in each step of Ba-TN sintering. It was found that up to temperature of $1050^{\circ} \mathrm{C}$ barium titanate exhibits fine ceramics grain size. At higher temperature grain morphology radically changes simultaneously with crystallographic phase composition change revealed by XRD and Raman studies.

\section{Conflicts of Interest}

The authors declare that they have no conflicts of interest.

\section{Acknowledgments}

This work was financially supported by National Science Center (Poland) grant awarded by Decision no. DEC2011/03/D/ST5/06074. Izabela Bobowska, Agnieszka Opasinska, and Jacek Ulanski acknowledge financial support by Foundation for Polish Science, Grant Master 9./2013.

\section{References}

[1] M. T. Sebastian, in Dielectric materials for wireless communication, Elsevier B.V, Great Britain, 1st edition, 2008.

[2] D. J. Masse, R. A. Pucel, D. W. Readey, E. A. Maguire, and C. P. Hartwig, "A New Low-Loss High-K Temperature-Compensated Dielectric for Microwave Applications," Proceedings of the IEEE, vol. 59, no. 11, pp. 1628-1629, 1971.

[3] S. G. Mhaisalkar, W. E. Lee, and D. W. Readey, "Processing and Characterization of BaTi4O9," Journal of the American Ceramic Society, vol. 72, no. 11, pp. 2154-2158, 1989.

[4] S. G. Mhaisalkar, D. W. Readey, and S. A. Akbar, "Microwave Dielectric Properties of Doped BaTi4O9," Journal of the American Ceramic Society, vol. 74, no. 8, pp. 1894-1898, 1991.

[5] M. Cernea, E. Chirtop, D. Neacsu, I. Pasuk, and S. Iordanescu, "Preparation of BaTi4O9 from oxalates," Journal of the American Ceramic Society, vol. 85, no. 2, pp. 499-503, 2002.

[6] J. Choy, Y. Han, J. Sohn, and M. Itoh, "Microwave Characteristics of $\mathrm{BaO}-\mathrm{TiO} 2$ Ceramics Prepared via a Citrate Route," Journal of the American Ceramic Society, vol. 78, no. 5, pp. 11691172, 1995.

[7] F. Li, L.-Q. Weng, G.-Y. Xu, S.-H. Song, and J. Yu, "Synthesis and characterization of microwave dielectric BaTi $4 \mathrm{O} 9$ ceramics via EDTA-citrate gel process," Materials Letters, vol. 59, no. 23, pp. 2973-2976, 2005.

[8] K. Fukuda, R. Kitoh, and I. Awai, "Microwave characteristics of mixed phases of BaTi4O9-BaPr2Ti4O12 ceramics," Journal of Materials Science, vol. 30, no. 5, pp. 1209-1216, 1995.

[9] E. Tillmanns, "Die Kristallstruktur von $\mathrm{BaTi}_{5} \mathrm{O}_{11}$," Acta Crystallographica Section B, vol. 25, p. 1444, 1969.

[10] J.-H. Choy, Y.-S. Han, J.-T. Kim, and Y.-H. Kim, "Citrate route to ultra-fine barium polytitanates with microwave dielectric properties," Journal of Materials Chemistry, vol. 5, no. 1, pp. 5763, 1995.

[11] H. Lu, L. E. Burkhart, and G. L. Schrader, "Sol-Gel Process for the Preparation of Ba2Ti9O20 and BaTi5O11," Journal of the American Ceramic Society, vol. 74, no. 5, pp. 968-972, 1991. 
[12] T. Fukui, C. Sakurai, and M. Okuyama, "Effects of heating rate on sintering of alkoxide-derived BaTi5O11 powder," Journal of Materials Research, vol. 7, no. 1, pp. 192-196, 1992.

[13] S.-F. Wang, Y.-F. Hsu, T.-H. Ueng, C.-C. Chiang, J. P. Chu, and C.-Y. Huang, "Effects of additives on the microstructure and dielectric properties of Ba2Ti9O20 microwave ceramic," Journal of Materials Research, vol. 18, no. 5, pp. 1179-1187, 2003.

[14] T.-T. Fang, J.-T. Shiue, and S.-C. Liou, "Formation mechanism and sintering behavior of Ba2Ti9O20," Journal of the European Ceramic Society, vol. 22, no. 1, pp. 79-85, 2002.

[15] K. P. Surendran, P. Mohanan, and M. T. Sebastian, "Tailoring the microwave dielectric properties of GdTiNb1-xTaxO6 and Sm1x YxTiTaO6 ceramics," Journal of the European Ceramic Society, vol. 23, no. 14, pp. 2489-2495, 2003.

[16] T. Sasaki, F. Kooli, M. Iida et al., "A mixed alkali metal titanate with the lepidocrocite-like layered structure. Preparation, crystal structure, protonic form, and acid-base intercalation properties," Chemistry of Materials, vol. 10, no. 12, pp. 4123-4128, 1998.

[17] W. A. England, J. E. Birkett, J. B. Goodenough, and P. J. Wiseman, "Ion exchange in the Csx[Ti2-x/2Mgx/2]O4 structure," Journal of Solid State Chemistry, vol. 49, no. 3, pp. 300-308, 1983.

[18] E. Chiellini, J. Sunamoto, C. Migliaresi, R. M. Ottenbrite, and D. Cohn, Biomedical Polymers and Polymer Therapeutics, Kluwer Academic Publishers, Boston, 2002.

[19] I. Bobowska, A. Opasińska, A. Wypych, and P. Wojciechowski, "Synthesis and dielectric investigations of $\mathrm{ZnTiO}_{3}$ obtained by a soft chemistry route," Materials Chemistry and Physics, vol. 134, no. 1, pp. 87-92, 2012.

[20] G. Pfaff, "Synthesis and characterization of BaTi4O9," Journal of Materials Science Letters, vol. 10, no. 3, pp. 129-131, 1991.

[21] T. Ohya, A. Nakayama, T. Ban, Y. Ohya, and Y. Takahashi, "Synthesis and characterization of halogen-free, transparent, aqueous colloidal titanate solutions from titanium alkoxide," Chemistry of Materials, vol. 14, no. 7, pp. 3082-3089, 2002.

[22] T. Gao, H. Fjellvag, and P. Norby, Journal of Physical Chemistry $B$, vol. 112, p. 9400, 2008.

[23] N. Li, L. Zhang, Y. Chen, M. Fang, J. Zhang, and H. Wang, "Highly efficient, irreversible and selective ion exchange property of layered titanate nanostructures," Advanced Functional Materials, vol. 22, no. 4, pp. 835-841, 2012.

[24] M. Rössel, H.-R. Höche, H. S. Leipner et al., "Raman microscopic investigations of $\mathrm{BaTiO} 3$ precursors with core-shell structure," Analytical and Bioanalytical Chemistry, vol. 380, no. 1, pp. 157-162, 2004.

[25] J. Javadpour and N. G. Eror, "Raman Spectroscopy of Higher Titanate Phases in the BaTiO3-TiO2 System," Journal of the American Ceramic Society, vol. 71, no. 4, pp. 206-213, 1988.

[26] Y. Xu, X. Yuan, G. Huang, and H. Long, "Polymeric precursor synthesis of Ba2Ti9O20," Materials Chemistry and Physics, vol. 90, no. 2-3, pp. 333-338, 2005.

[27] F. H. Chung, Journal of Applied Crystallography, vol. 7, p. 519, 1974.

[28] S. Kumar, V. S. Raju, and T. R. N. Kutty, "Preparation of BaTi4O9 and $\mathrm{Ba} 2 \mathrm{Ti} 9 \mathrm{O} 20$ ceramics by the wet chemical gel-carbonate method and their dielectric properties," Materials Science and Engineering B: Solid-State Materials for Advanced Technology, vol. 142, no. 2-3, pp. 78-85, 2007.

[29] C.-L. Huang, M.-H. Weng, C.-T. Lion, and C.-C. Wu, "Low temperature sintering and microwave dielectric properties of $\mathrm{Ba}$ 2Ti 9020 ceramics using glass additions," Materials Research Bulletin, vol. 35, no. 14-15, pp. 2445-2456, 2000.
[30] K. W. Kirby and B. A. Wechsler, "Phase relations in the Barium Titanate-Titanium Oxide System," Journal of the American Ceramic Society, vol. 74, no. 8, pp. 1841-1847, 1991. 

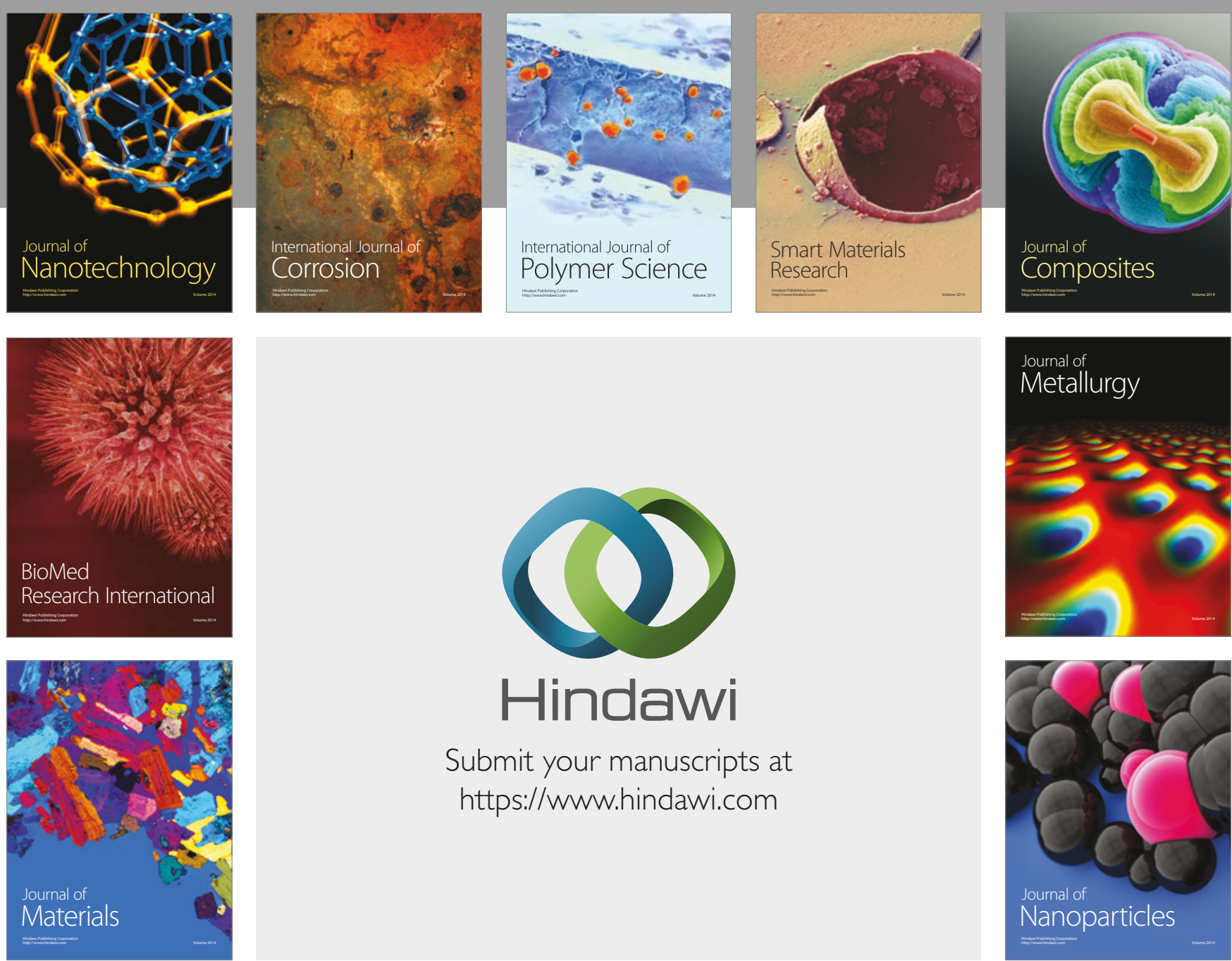

\section{Hindawi}

Submit your manuscripts at

https://www.hindawi.com
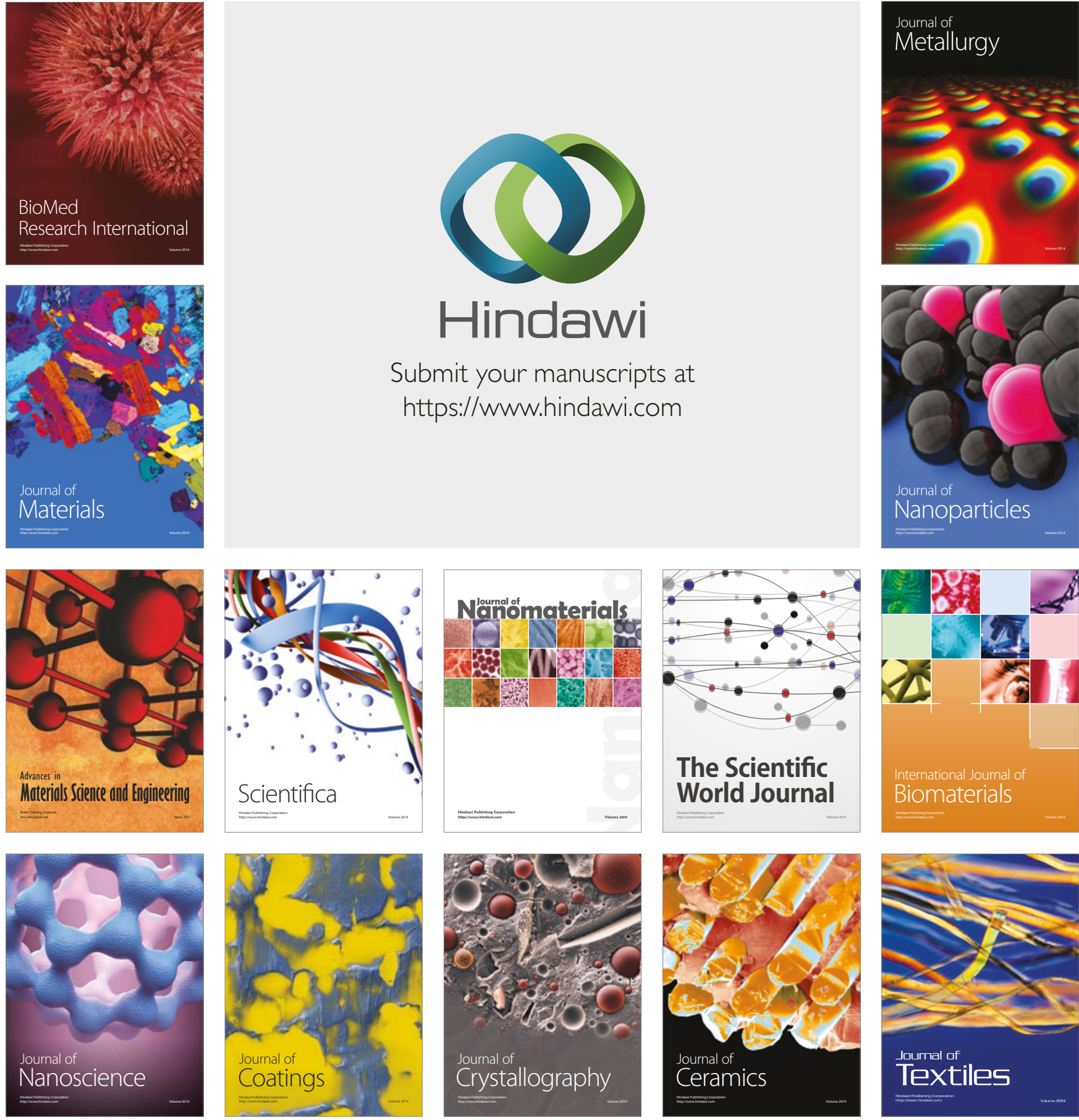

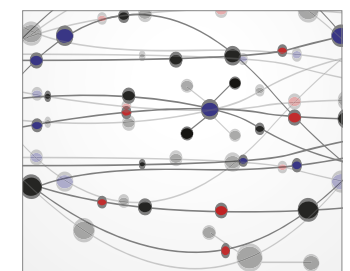

The Scientific World Journal
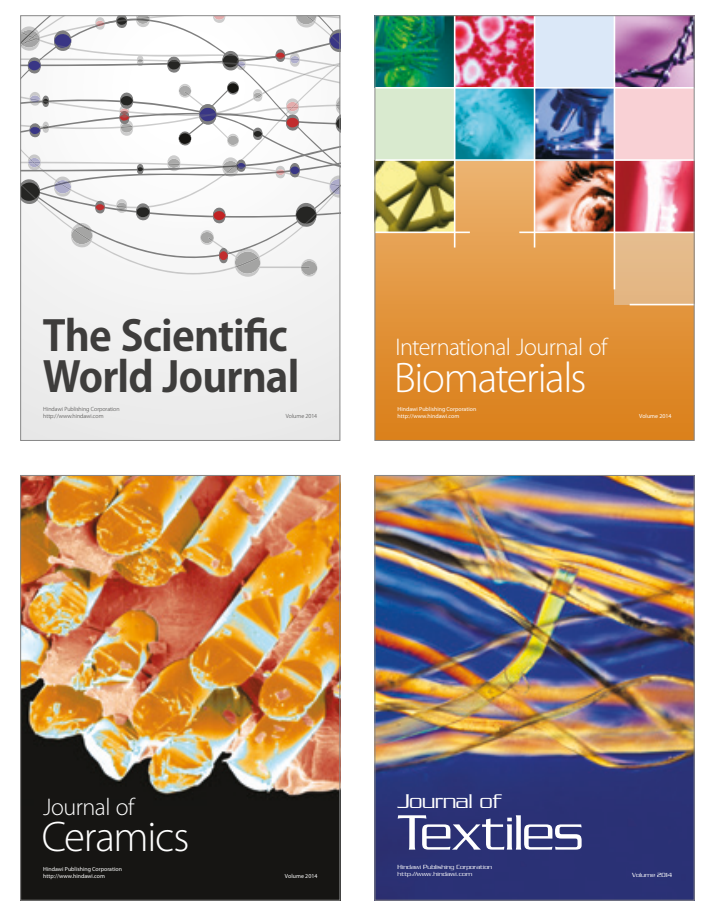